2 Madersbacher S, Alivizatos G, Nordling J, Rioja Sanz C, Emberton M, De la Rosette JJMCH. EAU 2004 guidelines on assessment, therapy and follow-up of men with lower urinary tract symptoms suggestive of benign prostatic hyperplasia (BPH guidelines). Eur Urol 2004;46:547-54.

3 Brown CT, Van der Meulen J, Mundy AR, Emberton M. Lifestyle and behavioural interventions for men on watchful waiting with uncomplicated lower urinary tract symptoms: a national multidisciplinary survey. BJU Int 2003:92:53-7.

4 Brown CT, Van der Meulen J, Mundy AR, O’Flynn E, Emberton M. Defining the components of a self-management programme for men with uncomplicated lower urinary tract symptoms: a consensus approach. Eur Urol 2004;46:254-63.

5 Barry MJ, Fowler FJ Jr, O’Leary MP, Bruskewitz RC, Holtgrewe HL,
Mebust WK, et al. The American Urological Association symptom index for benign prostatic hyperplasia. J Urol 1992;148:1549-57.

6 Barry MJ, Williford WO, Chang Y, Machi M, Jones KM, Walker-Corkery $\mathrm{E}$, et al. Benign prostatic hyperplasia specific health status measures in clinical research: how much change in the American Urological Association symptom index and the benign prostatic hyperplasia impact index is perceptible to patients? J Urol 1995;154:1770-4.

7 Barry MJ, Fowler FJ Jr, O'Leary MP, Bruskewitz RC, Holtgrewe HL, Mebust WK. Measuring disease-specific health status in men with benign prostatic hyperplasia. Med Care 1995;33:135-45.

8 Campbell M, Fitzpatrick R, Haines A, Kinmonth AL, Sandercock P, Spiegelhalter D, et al. Framework for design and evaluation of complex interventions to improve health. BMJ 2000;321:694-6. Accepted: 13 October 2006

\title{
Provision of taped conversations with neonatologists to mothers of babies in intensive care: randomised controlled trial
}

\author{
Tieh Hee Hai Guan Koh,, Phyllis N Butow, ${ }^{2}$ Michael Coory, ${ }^{3}$ Donna Budge, ${ }^{4}$ Li-An Collie, ${ }^{4}$ John Whitehall,, \\ Martin H Tattersall ${ }^{5}$
}

\section{EDITORIAL p1}

1'Institute of Women's and

Children's Health, Townsville

Hospital, Douglas, QLD 4814,

Australia, and Medical School of

James Cook University, Douglas,

QLD

${ }^{2}$ Medical Psychology Research

Unit, University of Sydney, NSW

Australia

${ }^{3}$ School of Population Health,

Queensland Health, Brisbane,

Australia

${ }^{4}$ Institute of Women's and

Children's Health, Townsville

Hospital, Douglas

${ }^{5}$ Faculty of Medicine, University of Sydney

Correspondence to: TH H G Koh

guan_koh@health.qld.gov.au

BMJ 2007;334:28-31

doi=10.1136/bmj.39017.675648.BE
This is the abridged version of an article that was posted on bmj. com on 1 December 2006. Cite this version as BMJ 1 December 2006 , doi: 10.1136/bmj.39017.675648. $\mathrm{BE}$ (abridged text, in print: BMJ 2007;334:28-31)

\section{ABSTRACT}

Objective To determine whether providing mothers of babies in neonatal intensive care units with audiotapes of their conversations with a neonatologist improves recall of information and psychological wellbeing.

Design Randomised, single blinded trial.

Setting Neonatal intensive care unit, north Queensland, Australia.

Participants 200 mothers of babies in a neonatal intensive care unit.

Interventions Mothers given ( $\mathrm{n}=102)$ or not given $(\mathrm{n}=98)$ audiotapes of their conversations with a neonatologist. Main outcome measures Recall of information, attitudes to and use of the tape, satisfaction with conversations, postnatal depression, anxiety, general health, and stress about parenting, at 10 days and four and 12 months. Results $91 \%(n=93)$ of mothers in the tape group listened to the tape (once by day 10 , twice by four months, and three times by 12 months; range 1-10). At 10 days and four months, mothers in the tape group recalled significantly more information about diagnosis, treatment, and outcome than mothers in the control group. At four months mothers in the tape group were $75 \%$ more likely to recall all of the information about treatment than mothers in the control group (59\% v $34 \%$; risk ratio 1.75, $95 \%$ confidence interval 1.27 to 2.4 ). Six mothers, all in the control group, could not recall their conversations. No statistically significant differences were found between the groups in satisfaction with conversations ( 10 days), postnatal depression and anxiety scores (10 days, four and 12 months), and stress about parenting (12 months).

Conclusion Providing the mothers of babies in neonatal intensive care units with audiotapes of conversations with a neonatologist enhanced their recall of information (up to four months). The taped conversations did not affect the mothers' wellbeing or satisfaction with the neonatologist.

Trial registration Australian Clinical Trials Registry 12606000478516.

\section{INTRODUCTION}

Several studies have found that giving adults with cancer an audiotape of their initial conversations with oncologists improved their psychological distress, anxiety, satisfaction with conversations, and recall of information whereas other authors found no benefits. ${ }^{1-7}$ We carried out a randomised single blind trial to compare the effects of providing or not providing mothers of babies in neonatal intensive care units with an audiotape of their conversations with the neonatologist.

\section{METHODS}

Mothers were eligible for the study if their babies were admitted to the neonatal intensive care unit at the Townsville Hospital, the regional neonatal unit for north Queensland (see bmj.com). The study was a randomised controlled trial of audiotape provision, with the neonatal team blinded to allocation. Before the first conversation the mothers completed a questionnaire eliciting personal details, anxiety scores, and preferences for information and involvement in decision making. A randomisation service then allocated the mother to receive or not to receive a tape of their conversations with a neonatologist.

After randomisation the initial conversation and subsequent conversations of significance were taped and analysed. The mothers in the experimental arm received a tape of each of the conversations and a tape recorder.

Ten days and four months after the initial conversation the researcher interviewed the mothers to document their recall of the diagnosis, tests, treatment, and outcome of their babies as conveyed by the neonatologist. Mothers also completed a questionnaire to ascertain views of the taping, use of the tapes, anxiety, general health, depression, marital satisfaction, social support, and satisfaction with conversations held with 
the neonatologist. At 12 months the mothers were given the same questionnaire.

\section{Outcome measures}

Recall of information was assessed by face to face or telephone interview, which opened with a question inviting mothers to report what the neonatologist had told them and their understanding of the meaning. Transcripts of the conversations were coded by a neonatologist (THHGK).

We used the Spielberger state anxiety inventory to measure anxiety, the Edinburgh postnatal depression scale to measure postnatal depression, and the general health questionnaire to measure psychological morbidity. ${ }^{8-10}$ To measure stress associated with the child and with parenting we summed the scores for each child and parent domain of the parental stress index, the total score being the sum of the two domains. ${ }^{11}$

We used a five point Likert scale to assess satisfaction with the amount and quality of information presented, doctors' communication skills, and the patient's participation in the conversation. ${ }^{12}$ Satisfaction with the tape was measured using a scale based on usefulness of tapes to patients with cancer. ${ }^{13}$ We elicited information and preferences for involvement using a scale assessing the type and amount of information required and the level of involvement in decision making. ${ }^{14}$ Satisfaction with an intimate relationship was measured using the

Table 1 | Mothers having $100 \%$ recall about diagnosis, tests, treatment, and outcome of their babies in a neonatal intensive care unit, at 10 days and four months follow up, according to group. Values are numbers (percentages) unless stated otherwise

\begin{tabular}{lllll}
$\begin{array}{l}\text { Follow up } \\
10 \text { days: }\end{array}$ & Tape group $(\mathrm{n=102)}$ & Control group $(\mathrm{n}=98)$ & Relative risk* $(95 \% \mathrm{Cl})$ & Pvalue \\
\hline Diagnosis & $73(72)$ & $52(53)$ & $1.35(1.08$ to 1.69$)$ & 0.007 \\
\hline Tests & $43(42)$ & $39(40)$ & $1.06(0.63$ to 1.94$)$ & 0.734 \\
\hline Treatment & $64(63)$ & $47(48)$ & $1.83(1.04$ to 3.21$)$ & 0.035 \\
\hline Outcome & $84(82)$ & $65(66)$ & $1.24(1.05$ to 1.47$)$ & 0.009 \\
\hline m months: & & & $1.27(0.99$ to 1.63$)$ & 0.05 \\
\hline Diagnosis & $65(64)$ & $49(50)$ & $1.35(1.00$ to 1.84$)$ & 0.045 \\
\hline Tests & $45(44)$ & $35(36)$ & $1.75(1.27$ to 2.4$)$ & 0.004 \\
\hline Treatment & $60(59)$ & $33(34)$ & $1.29(1.08$ to 1.55$)$ & 0.005 \\
\hline Outcome & $82(80)$ & $61(62)$ & &
\end{tabular}

*Value greater than 1.0 indicates higher recall in tape group.

Table 2 | Postnatal depression and psychological morbidity at follow-up in mothers of babies in a neonatal intensive care unit, according to group. Values are numbers (percentages) unless stated otherwise

\begin{tabular}{|c|c|c|c|c|}
\hline Measure & $\begin{array}{l}\text { Tape group } \\
(n=102)\end{array}$ & $\begin{array}{l}\text { Control group } \\
\qquad(n=98)\end{array}$ & $\begin{array}{l}\text { Relative risk } \\
(95 \% \mathrm{Cl})\end{array}$ & Pvalue \\
\hline \multicolumn{5}{|c|}{ Edinburgh postnatal depression score $>12^{\star}$ : } \\
\hline 10 days & $48(47)$ & $40(41)$ & 1.15 (0.84 to 1.58$)$ & 0.37 \\
\hline 4 months & $13(13)$ & $18(18)$ & $0.9(0.46$ to 1.76$)$ & 0.75 \\
\hline 12 months & $12(12)$ & $10(10)$ & $1.15(0.52$ to 2.5$)$ & 0.72 \\
\hline \multicolumn{5}{|c|}{ General health questionnaire score $>1 \dagger$ : } \\
\hline 10 days & $66(65)$ & $65(66)$ & 0.99 (0.8 to 1.2$)$ & 0.92 \\
\hline 4 months & $41(40)$ & $35(36)$ & 1.13 (0.8 to 1.6$)$ & 0.51 \\
\hline 12 months & $23(23)$ & $23(24)$ & 0.96 (0.6 to 1.6$)$ & 0.88 \\
\hline
\end{tabular}

*Mothers with score $>12$ most likely to have a depressive illness and should be further assessed.

to score for non-cases, 1 or greater for cases of greater distress. relational interaction satisfaction scale. ${ }^{15}$ For social support we used the Sarason social support questionnaire to assess the size of the support network and satisfaction with support. ${ }^{16}$

The clinical risk index for babies is a scoring system predicting mortality in hospital among high risk babies in neonatal intensive care units. ${ }^{17}$ We documented severity of illness at birth and common neonatal complications.

\section{Statistical analysis}

We collected and analysed the data on an intention to treat basis using SPSS version 10.0.5 for Windows. Analyses were two tailed, with the significance set at 0.05 .

For dichotomous variables we counted missing data as failures in the intervention group and successes in the control group whereas for continuous variables we set missing values to the mean of the other group. We used linear and logistic multiple regression to analyse the effects of tape provision on mother's psychological outcomes, controlling for imbalances in baseline characteristics between the groups. Subgroup analyses were according to whether the babies had good or poor outcomes.

\section{RESULTS}

Between July 1999 and December 2001200 of 256 $(78 \%)$ mothers of babies admitted to the Townsville Hospital neonatal intensive care unit agreed to participate: 102 were randomised to receive audiotapes of their conversations with a neonatologist and 98 were randomised to no tape (see bmj.com).

Baseline characteristics of the mothers and babies were similar in both groups except that mothers randomised to receive the tape were more likely to have had less education than those in the control group (see bmj.com). Measures of mothers' baseline preferences for information and role in decision making, anxiety, and social support showed no significant differences between the groups. The modal number of conversations taped was one per mother (range 1-11), and no significant differences were found between the groups.

Most (84-98\%) of the mothers in both groups responded that having their conversations taped did not annoy or embarrass them or cause anxiety. Most $(71-92 \%)$ of the mothers given the tapes stated that they helped their understanding, reminded them of what had been said, and helped their family to understand and recall information. Mothers listened to the tape a modal of once by 10 days, twice by four months, and three times by 12 months (range 1-10 for each assessment).

At 10 days and four months mothers in the tape group had significantly greater recall of information on the diagnosis or outcome of the baby and on tests or treatment, respectively (table 1). The difference between the two groups remained significant in multivariate analysis. Six mothers, all in the control group, could not recall any information.

With and without adjustment for baseline differences, no differences were found between the two groups in 
Table 3 | Psychological wellbeing and stress about parenting of mothers with babies in a neonatal intensive care unit with a poor outcome. Values are percentages (numbers) of mothers unless stated otherwise

\begin{tabular}{lcccc}
$\begin{array}{l}\text { Measure } \\
\text { Edinburgh postnatal depression score } 12^{*}:\end{array}$ & Tape group & Control group & Relative risk $(95 \% \mathrm{Cl})$ & Pvalue \\
\hline 10 days & $60(12 / 20)$ & $36(5 / 14)$ & $1.68(076$ to 3.7$)$ & 0.16 \\
\hline 4 months & $33(6 / 18)$ & $20(2 / 12)$ & $0.64(0.29$ to 1.45$)$ & 0.31 \\
\hline 12 months & $19(3 / 16)$ & $27(3 / 11)$ & $0.69(0.17$ to 2.8$)$ & 0.60 \\
\hline General health questionnaire score 11 t: & & & & \\
\hline 10 days & $79(15 / 19)$ & $71(10 / 14)$ & $1.1(0.73$ to 1.7$)$ & 0.62 \\
\hline 4 months & $56(10 / 18)$ & $50(6 / 12)$ & $1.1(0.55$ to 2.2$)$ & 0.76 \\
\hline 12 months & $40(6 / 15)$ & $50(6 / 12)$ & $0.8(0.35$ to 1.9$)$ & 0.60 \\
\hline Parenting stress index score $85 \% \neq:$ & & & & \\
\hline Child domain & $40(2 / 5)$ & $25(2 / 8)$ & $1.6(0.32$ to 8.0$)$ & 0.57 \\
\hline Parents domain & $67(1015)$ & $90(9 / 10)$ & $0.74(0.49$ to 1.1$)$ & 0.18 \\
\hline
\end{tabular}

*Mothers with score $>12$ most likely to have a depressive illness and should be further assessed.

t0 score for non-cases, 1 or greater for cases of greater distress.

¥Score greater than $85 \%$ indicating greater stress.

Table 4 | Anxiety and satisfaction with conversation with a neonatologist of mothers with babies in a neonatal intensive care unit with a poor outcome

\begin{tabular}{lccc} 
Measure & \multicolumn{1}{c}{$\begin{array}{c}\text { Tape group } \\
\text { (No of mothers) }\end{array}$} & $\begin{array}{c}\text { Control group } \\
\text { (No of mothers) }\end{array}$ & Significance \\
$\begin{array}{l}\text { Mean (SD) state and anxiety } \\
\text { inventory score: }\end{array}$ & $48.0(13.4)(\mathrm{n}=20)$ & $43.9(14.9)(\mathrm{n}=14)$ & $\mathrm{P}=0.8, t=0.41$ \\
\hline 10 days & $39.3(12.6)(\mathrm{n}=20)$ & $35.3(12.0)(\mathrm{n}=14)$ & $\mathrm{P}=0.29, t=1.1$ \\
\hline 4 months & $34.73(10.8)(\mathrm{n}=19)$ & $33.4(8.2)(\mathrm{n}=13)$ & $\mathrm{P}=0.71, t=0.38$ \\
\hline 12 months & $115(104$ to 123.2$)(\mathrm{n}=19)$ & $\begin{array}{r}100.5(94.1 \text { to } 109.4) \\
(\mathrm{n}=14)\end{array}$ & $\mathrm{P}=0.0051, \chi_{1}^{2}=7.8$ \\
\hline $\begin{array}{l}\text { Mean }(95 \% \mathrm{Cl}) \text { satisfaction with } \\
\text { conversation }\end{array}$ & &
\end{tabular}

the incidence of postnatal depression, anxiety scores, general psychological wellbeing, parenting stress, and satisfaction with conversation (table 2 and bmj.com).

For babies with a good outcome significantly more mothers in the tape group compared with the control group had $100 \%$ recall of information at 10 days of their babies' treatment or outcome and at four months of their babies' diagnosis, treatment, or outcome (see bmj.com). For babies with a poor outcome no differences were found between the groups in recall of information at 10 days whereas at four months significantly more mothers in the tape group had 100\% recall of information of their babies' treatment (see bmj.com). No differences were found between the two groups in maternal psychological wellbeing and parenting stress for babies with a poor outcome (tables 3 and 4). Mothers of babies with a poor outcome in the tape group were, however, significantly more satisfied with the conversation (table 4).

\section{DISCUSSION}

Providing the mothers of babies in a neonatal intensive care unit with an audiotape of their conversations with a neonatologist improved their recall of information at 10 days and four months. The tapes did not influence parental wellbeing or stress about parenting. The mothers of babies with a poor outcome who received the tape were significantly more satisfied with the conversation.

The mothers in our study attended a regional neonatal intensive care unit, were prospectively recruited, and were followed up to one year. The cohort included a racially and socioeconomically diverse sample of mothers whose babies had a wide spectrum of clinical conditions. The incidence of postnatal depression at the three follow-up periods (10 days and four and 12 months) was similar to that reported among mothers with babies in neonatal intensive care units in another study, suggesting that our cohort is representative of such mothers. ${ }^{18}$

Most of the mothers in both groups were positive about having their conversations with the neonatologist taped. Overall, $96 \%$ of mothers listened to the tapes and found them helpful in recalling information. The tapes improved recall of information up to four months. That six of the mothers in the control group could not recall their conversations has important medicolegal implications. ${ }^{19}$

The mothers of babies with poor outcome did not seem to be helped by the tapes at 10 days' follow-up; at four months, however, these mothers recalled significantly more information on the treatment and outcome of their babies compared with the control group. This may have been due to the mothers being in shock about their babies' condition and needing time to adjust to their situation. Mothers of babies with a poor outcome were significantly more satisfied with the conversation than mothers in the control group. The results need to be interpreted with caution, however, as the number of mothers with babies given a poor outcome was small.

No significant difference was found between the groups for postnatal depression, anxiety, psychological wellbeing, or parenting stress scores at 10 days and four and 12 months. Thus the benefits to recall do not seem to be associated with negative psychological effects.

The limitations of our study include a higher refusal rate for non-white mothers. No significant differences were, however, found between the groups in the proportion of mothers who were non-white. The trial involved three neonatologists so the results may be different with other neonatologists.

\section{Conclusion}

It is practical to tape conversations between the mothers of babies in neonatal intensive care units and neonatologists. In our study the tapes were listened to by both the mothers and family members. At 10 days' and four months' follow-up the tapes improved the mothers' recall of information provided by the neonatologist and did not influence their wellbeing or stress about parenting. The mothers of babies with poor outcome who received the tapes were significantly more satisfied with the conversation than similar mothers in the control group.

We thank the mothers and health professionals at the Institute of Women's and Children's Health, Townsville Hospital, for their support.

Contributors: See bmj.com.

Funding: THHGK, PNB, DB, LC, JW, and MHT were supported by grants from the Royal Children's Hospital Foundation/Golden Casket, Brisbane and the Townsville health district.

Competing interests: None declared.

Ethical approval: This study was approved by Townsville health district ethics committee. 


\section{WHAT IS ALREADY KNOWN ON THIS TOPIC}

Parents of babies in a neonatal intensive care unit have problems recalling information No randomised controlled trials have assessed the effects of providing parents with tapes of their conversations with neonatologists

\section{WHAT THIS STUDY ADDS}

Providing mothers of babies in neonatal intensive care units with tapes of conversations with neonatologists improves their recall of information

The tapes did not affect the mothers' wellbeing or satisfaction with the neonatologist

1 Butt HR. A method for better physician-patient communication. Ann Intern Med 1977:86:478-80.

2 Scott JT, Harmsen M, Prictor MJ, Entwistle VA, Sowden AJ, Watt I. Recordings or summaries of conversations for people with cancer. Cochrane Database Syst Rev 2003;(2):CD001539.

3 Tattersall MH, Butow PN. Conversation audio tapes: an underused cancer patient information aid and clinical research tool. Lancet Oncol 2002;3:431-7.

4 Ong LM, Visser MR, Lammes FB, van Der Velden J, Kuenen BC, de Haes JC. Effect of providing cancer patients with the audiotaped initial conversation on satisfaction, recall, and quality of life: a randomized, double-blind study. J Clin Oncol 2000;18:3052-60.

5 Hogbin B, Jenkins VA, Parkin AJ. Remembering 'bad news' consultations: an evaluation of tape-recorded consultations. PsychoOncology 1992;1:147-54.

6 McHugh P, Lewis S, Ford S, Newlands E, Rustin G, Coombes C, et al. The efficacy of audiotapes in promoting psychological well-being in cancer patients: a randomised, controlled trial. Brit/ Cancer 1995;71:388-92.

7 Koh THHG, Budge D, Butow P, Renison B, Woodgate P. Audio recordings of conversations with doctors for parents of critically sick babies. Cochrane Database Syst Rev 2005;(1):CD004502.

8 Spielberger CD, Gorsuch RL, Lushene RE. Manual for the state-trait anxiety inventory. Palo Alto, CA: Consulting Psychologists Press, 1970.

9 Development of the 10-item Edinburgh postnatal depression scale. $B$ Psychiatry 1987;150:782-6.

10 Goldberg DP, HillierVF. A scaled version of the general health questionnaire. Psychol Med 1979;9:139-45.

11 Abidin RR. Parenting stress index-manual. Charlottesville VA: Pediatric Psychology Press, 1990.

12 Brown R, Dunn S, Butow P. Meeting patient expectations in the cancer conversation. Ann Oncol 1997;8:877-82.

13 Tattersall MH, Butow PN, Griffin AM, Dunn SM. The take-home message: patients prefer conversation audiotapes to summary letters. J Clin Oncol 1994;12:1305-11.

14 Cassileth BR, Zupkis RV, Sutton-Smith K, March V. Information and participation preferences among cancer patients. Ann Intern Med 1980;92:832-6.

15 Buunk BP. Relationship interaction satisfaction scale. In: Touliatos J, Perlmutter BF, Straus MA, eds. Handbook offamily measurement techniques. Newbury Park, CA: Sage, 1990:106-7.

16 Sarason I, Sarason B, Shearin E, Pierce G. A brief measure of social support: practical and theoretical implications. J Soc Pers Relat 1987:4:497-510.

17 Anon. CRIB (clinical risk index for babies), mortality, and impairment after neonatal intensive care. Scottish Neonatal Consultants' Collaborative Study Group and the International Neonatal Network. Lancet 1995;345:1020-2.

18 Hagan R, Evans SF, Pope S. Preventing postnatal depression in mothers of very preterm infants: a randomised controlled trial. BritJ Obstetr Gynaecol 2004;111:641-7.

19 Snowdon C, Garcia J, Elbourne D. Making sense of randomization; responses of parents of critically ill babies to random allocation of treatment in a clinical trial. Soc Sci Med 1997;45:1337-55.

Accepted: 13 October 2006
National Primary Care Research and Development Centre, Centre for Health Economics, University of York, York Y010 5DD

2University of Plymouth, Peninsula Allied Health Centre, College of St Mark and St John, Plymouth PL6 8BH

${ }^{3}$ Manchester Business School, University of Manchester

Manchester M156PB

${ }^{4}$ National Primary Care Research and

Development Centre, University of

Manchester, Manchester M139PL

${ }^{5}$ Sheffield Institute for Studies of

Ageing, University of Sheffield,

Barnsley Hospital NHS Foundation

Trust, Barnsley S752EP

Correspondence to: $\mathrm{M}$ Roland

m.roland@manchester.ac.uk

BMJ 2007;334:31-4

doi=10.1136/bmj.390120.413310.55

This article is the abridged version of a paper that was published on bmj.com on 15 November 2006. Cite this version as $B M / 15$ November 2006, doi: $10.1136 /$ bmj.39020.413310.55 (abridged text, in print: $B M J$ 2007:334:31-4)

\title{
Impact of case management (Evercare) on frail elderly patients: controlled before and after analysis of quantitative outcome data
}

\author{
Hugh Gravelle, ${ }^{1}$ Mark Dusheiko, ${ }^{1}$ Rod Sheaff, ${ }^{2}$ Penny Sargent, ${ }^{3}$ Ruth Boaden, ${ }^{3}$ Susan Pickard, ${ }^{4}$ Stuart Parker, \\ Martin Roland ${ }^{4}$
}

\section{ABSTRACT}

Objectives To determine the impact on outcomes in patients of the Evercare approach to case management of elderly people.

Design Practice level before and after analysis of hospital admissions data with control group.

Setting Nine primary care trusts in England that, in 2003-5, piloted case management of elderly people selected as being at high risk of emergency admission.

Main outcome measures Rates of emergency admission, emergency bed days, and mortality from April 2001 to March 2005 in 62 Evercare practices and 6960-7695 control practices in England (depending on the analysis being carried out).

Results The intervention had no significant effect on rates of emergency admission (increase 16.5\%, 95\% confidence interval $-5.7 \%$ to $38.7 \%$ ), emergency bed days (increase $19.0 \%,-5.3 \%$ to $43.2 \%$ ), and mortality (increase $34.4 \%$, $-1.7 \%$ to $70.3 \%$ ) for a high risk population aged $>65$ with a history of two or more emergency admissions in the preceding 13 months. For the general population aged $\geq 65$ effects on the rates of emergency admission (increase $2.5 \%$, $-2.1 \%$ to $7.0 \%$ ), emergency bed days (decrease $-4.9 \%$, $-10.8 \%$ to $1.0 \%$ ), and mortality (increase $5.5 \%,-3.5 \%$ to
$14.5 \%)$ were also non-significant.

Conclusions Case management of frail elderly people introduced an additional range of services into primary care without an associated reduction in hospital admissions. This may have been because of identification of additional cases. Employment of community matrons is now a key feature of case management policy in the NHS in England. Without more radical system redesign this policy is unlikely to reduce hospital admissions.

\section{INTRODUCTION}

Case management of frail elderly people was recently introduced into the NHS and subsequently became a key component of the national community matron policy. ${ }^{1}$ Case management aims to improve outcomes in patients and, in particular, to reduce unplanned hospital admission.

Systematic reviews of home based support for older people have drawn mixed conclusions from no overall impact on hospital admission ${ }^{2}$ to reduced admission rates and costs, dependent on the system of care. ${ }^{3}$ Two further reviews concluded that there is limited evidence that case management of elderly people can reduce use of health services, but both suggest that the results from 